\title{
CDISC SDTM Hepatic Findings About Test Code Terminology
}

National Cancer Institute

\section{Source}

National Cancer Institute. CDISC SDTM Hepatic Findings About Test Code Terminology. NCI Thesaurus. Code C117739.

Terminology associated with the hepatic findings about test codes codelist of the Clinical Data Interchange Standards Consortium (CDISC) Study Data Tabulation Model (SDT M). 